\title{
Hérnia traumática do pulmão
}

\section{Traumatic lung hernia}

Giovanni Antonio Marsico TCBC-RJ'; Carlos Henrique Ribeiro Boasquevisque²; Gustavo lucas Loureiro33; Rodrigo Fellpe Marques³; Antonio Miraldi Clemente ${ }^{5}$

\section{INTRODUÇÃO}

A hérnia pulmonar é definida como a protrusão de tecido pulmonar pela abertura anormal existente na parede torácica. A hérnia pulmonar traumática é ocorrência rara, na literatura encontramos aproximadamente o relato de 300 casos. Foi descrita pela primeira vez por Rolando em 1499 e classificada em 1845 por Morel-Lavalle ${ }^{1-3}$.

Relatamos o diagnóstico e o tratamento de um caso de hérnia pulmonar traumática.

\section{RELATO DO CASO}

Homem, branco, 51 anos de idade. Relatava queda de bicicleta há um ano com impacto direto do guidom na região anterior do hemitórax esquerdo. Desde então passou a referir dor na região paraesternal esquerda na altura do segundo espaço intercostal. Após algum tempo, notou que nesse local, durante a realização de esforço com a tosse, surgia uma tumoração. No exame físico foi identificada flacidez da parede torácica anterior no segundo espaço intercostal esquerdo. Durante a manobra de Valsalva ocorria o surgimento de tumoração de consistência esponjosa com cerca de $10 \mathrm{~cm}$ de diâmetro que era facilmente redutível (Figura 1). Com o diagnóstico de hérnia pulmonar traumática foi indicada a correção cirúrgica. Com o paciente em decúbito dorsal e sob anestesia geral com tubo orotraqueal de luz única, foi realizada incisão transversa sobre o segundo espaço intercostal esquerdo com cerca de $7 \mathrm{~cm}$ de extensão. Encontramos flacidez importante da musculatura da parede nessa região, pleura parietal rompida e fratura da cartilagem do terceiro arco costal esquerdo, o que permitia facilmente a saída do pulmão (Figura 2). A correção do defeito consistiu na aproximação do segundo e do terceiro arcos costais com quatro fios de prolene 2, reduzindo assim o espaço intercostal. Foram aplicados pontos com fio monofilamentar absorvível no músculo peitoral maior para diminuir a flacidez do próprio. Deixado dreno torácico na cavidade pleural que foi retirado

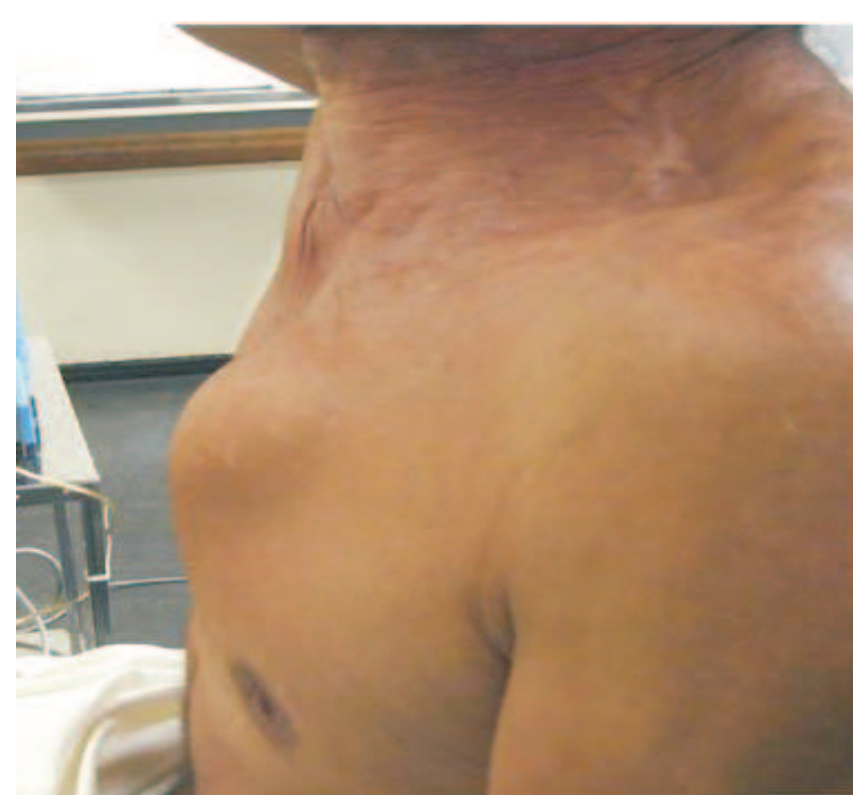

Figura 1 - Tumoração na parede anterior do tórax que surge durante a manobra de Valsalva.

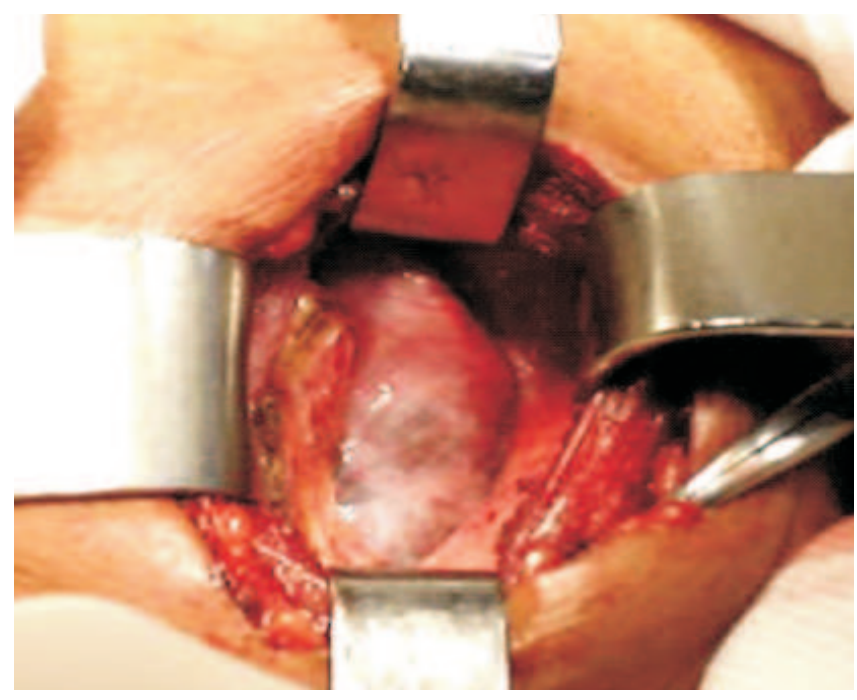

Figura 2 - Pleura parietal rompida e fratura da cartilagem do terceiro arco costal esquerdo. Aumento do espaço intercostal permitindo a migração do pulmão.

Trabalho realizado na Divisão de Cirurgia Torácica do Instituto De Doenças Do Tórax - Universidade Federal Do Rio de Janeiro, IDT-UFRJ. 1. Chefe da Divisão de Cirurgia Torácica - IDT-UFRJ; 2. Professor Adjunto de Cirurgia Torácica - IDT-UFRJ; 3. Ex-Residente em Cirurgia Torácica - IDT-UFRJ; 4. Ex-Residente em Cirurgia Torácica - IDT-UFRJ; 5. Cirurgião Torácico - IDT-UFRJ; Chefe do Serviço de Cirurgia Torácica do Hospital de Força Aérea do Galeão Rio de Janeiro - HFAG 
após 24 horas. O paciente obteve alta no terceiro dia de pós-operatório e, após oito meses de acompanhamento, estava assintomático e sem sinais de recidiva local.

\section{DISCUSSÃO}

A hérnia pulmonar pode ser classificada em congênita ou adquirida. Esta é dividida em espontânea, patológica, pós-cirurgia ou traumática. Aproximadamente, 20\% dos relatos são descrições de hérnias congênitas e $80 \%$ de adquiridas. A hérnia espontânea esta associada ao aumento da pressão intratorácica com a tosse, manobra de Valsalva ou durante levantamento de pesos. Os fatores predisponentes incluem doença pulmonar obstrutiva crônica, tosse vigorosa, hiperinsuflação pulmonar e uso crônico de esteróides. Os processos infecciosos ou neoplásicos, que ocorrem na parede torácica, podem ser causas de hérnia. Tem sido relatada, também, como secundária aos procedimentos operatórios, quedas, acidentes automobilísticos e traumas penetrantes. A localização mais comum da hérnia pulmonar pós-traumática é na parede anterior do tórax região paraesternal, enquanto que as congênitas ocorrem na região supraclavicular ${ }^{1-5}$.

A hérnia pulmonar traumática intercostal frequentemente esta associada a fraturas múltiplas de costelas e/ ou ao rompimento dos músculos intercostais. Embora possa ocorrer em outras regiões, geralmente, surge em locais adjacentes ao esterno na junção condroesternal, onde a musculatura intercostal é menos densa e os músculos intercostais externos estão ausentes. Diferente da musculatura existente na parede posterior, que é mais potente e, portanto, confere maior proteção. A identificação da hérnia pulmonar pode ser imediata ou retardada durante meses ou anos ${ }^{3,4}$
A hérnia pulmonar, geralmente, evolui com poucos sintomas. Em algumas ocasiões causa dor discreta e dispnéia. Percebe-se elevação e protrusão na parede torácica causada pela massa crepitante de consistência esponjosa, identificada durante a palpação. Constitui importante sinal diagnóstico o aumento da massa durante manobra de Valsalva e a tosse. O diagnóstico é predominantemente clínico, embora as radiografias de tórax realizadas em posição oblíqua e a tomografia computadorizada possam auxiliar na confirmação do diagnóstico, identificando a protrusão do pulmão ${ }^{3-5}$.

A queixa mais importante do nosso paciente era a dor referida na parede anterior do tórax à esquerda.

Em alguns poucos casos de hérnia pulmonar traumática a conduta é conservadora. A correção cirúrgica está sempre indicada nas hérnias volumosas, devido ao risco de encarceramento pulmonar, dor intratável e quando o aspecto não é aceito pelo paciente ${ }^{1,2}$. Embora o risco de encarceramento pulmonar seja destacado pela maioria dos autores, não encontramos relatos sobre essa intercorrência. A correção primária da hérnia pulmonar traumática possibilita bons resultados com a simples aproximação dos bordos da abertura e a reposição do pulmão na cavidade pleural. 0 uso do periósteo das costelas adjacentes pode auxiliar na correção. Somente os grandes defeitos na parede torácica necessitam da colocação de tela. Excepcionalmente a ressecção do pulmão encarcerado é necessária ${ }^{1,2}$.

Em nosso paciente o defeito na parede torácica foi corrigido pela simples aproximação das costelas, diminuindo assim o espaço intercostal que estava aumentado em decorrência de fratura da segunda cartilagem condroesternal.

O tratamento operatório precoce na hérnia pulmonar traumática é recomendado, em virtude da baixa morbidade e dos excelentes resultados obtidos $1,4,5$.

\section{A B S S T R A C}

Traumatic lung herniation is an unusual clinical problem. We present a case of a large left post-traumatic lung hernia on the left, anterior, second intercostal space following blunt chest trauma. An important factor in the etiology of these lesions is the relative lack of muscular support of the anterior part of the chest. This report describes the diagnosis and management of a post-traumatic lung hernia.

Key words: Hernia. Intercostal muscles. Thoracic injuries. Contusions. Lung Injury.

\section{REFERÊNCIAS}

1. Forty J, Wells C. Traumatic intercostal pulmonary hernia. Ann Thorac Surg. 1990;49(4):670-1.

2. Arstanian A, Oliaro A, Donati G, Filosso PL. Posttraumatic pulmonary hernia J Thorac Cardiovasc Surg. 2001;122(3):619-21.

3. Brock MV, Heitmiller RF. Spontaneous anterior thoracic lung hernias J Thorac Cardiovasc Surg. 2000;119(5):1046-7.

4. Allen GS, Fischer RP. Traumatic lung herniation. Ann Thorac Surg. 1997;63(5):1455-6.

5. Lang-Lazdunski L, Bonnet PM, Pons F, Brinquin L, Jancovici R. Traumatic extrathoracic lung herniation. Ann Thorac Surg. 2002;74(3):927-9
Recebido em 10/12/2006

Aceito para publicação em 10/02/2007

Conflito de interesse: nenhum

Fonte de financiamento: nenhuma

Como citar este artigo:

Marsico GA, Boasquevisque CHR, Loureiro GL, Marques RF, Clemente AM. Hérnia traumática do pulmão. Rev Col Bras Cir. [periódico na Internet] 2011; 38(1). Disponível em URL: http://www.scielo.br/rcbc

Endereço para correspondência:

Giovanni Antonio Marsico

E-mail: marsicog@gbl.com.br 